\title{
HLA Class II DNA Typing in a Large Series of European Patients with Systemic Lupus Erythematosus
}

\author{
Correlations with Clinical and Autoantibody Subsets
}

\author{
Mauro Galeazzi, Gian Domenico Sebastiani, Gabriella Morozzi, Carlo CarCassi, \\ Giovanni Battista Ferrara, Raffaella Scorza, Ricard Cervera, Enrique De Ramon Garrido, \\ Antonio Fernandez-Nebro, Frederic Houssiau, AnNa Jedryka-Goral, Giuseppe Passiu, \\ Chryssa Papasteriades, Jean-Charles Piette, Josef Smolen, Giovanni Porciello, Roberto Marcolongo, \\ AND THE EUROPEAN CONCERTED ACTION ON THE IMMUNOGENETICS OF SLE*
}

\section{Introduction}

The etiopathogenesis of systemic lupus erythematosus (SLE) is complex and still largely unknown. Genetic, environmental, and hormonal factors contribute to disease susceptibility (1). The importance of genetic factors is documented by 1) the pronounced difference in concordance rates between monozygotic and dizygotic twins (15); 2) the higher disease prevalence in relatives of patients with SLE (14);3) the

From Istituto di Reumatologia (MG, GM, RM, GP), Università di Siena, Siena; Divisione di Reumatologia (GDS), Ospedale San Camillo, Roma; Dipartimento di Genetica Medica (CC), Istituto di Clinica Medica, and II Cattedra di Reumatologia (GP), Dipartimento di Scienze Mediche, Centro Malattie Reumatiche Sistemiche, Università di Cagliari, Cagliari; Laboratorio di Immunogenetica (GBF), Istituto Nazionale per la Ricerca sul Cancro, Genova; Laboratorio di Immunologia Cellulare e Immunogenetica (RS), Istituto di Medicina Interna, Malattie Infettive e Immunopatologia, Università di Milano, Italy. Unitat de Malalties Autoimmunes Sistèmiques (RC), Hospital Clinic, Barcelona; Department of Medicine (EDRG), Lupus Unit, Universitary Hospital, Malaga; Unidad de Enfermedades Autoimmunes Sistemicas (AFN), Hospital Regional del SAS, Malaga, Spain. Service du Rhumatologie (FH), Cliniques Universitaires Saint-Luc, Université Catholique de Louvain, Bruxelles, Belgium. Department of Connective Tissue Diseases (AJG), Institute of Rheumatology, Warsaw, Poland. Department of Immunology and Histocompatibility (CP), Evangelismos Hospital, Athens, Greece. Service de Médecine Interne (JCP), CHU Pitié-Salpetrière, Paris, France. 2nd Department of Medicine (JS), Center for Rheumatic Diseases, Lainz Hospital, Vienna, Austria.

This study was supported by a grant from the European Union on the Immunogenetics of SLE (European Concerted Action on Immunogenetics of SLE-Biomed 1; contract BMH1-CT94-1260).

*European Concerted Action on the Immunogenetics of SLE (ECAISLE): 1) Istituto di Reumatologia, Università di Siena, Siena, Italy: M Galeazzi, R Marcolongo, G Morozzi, F Bellisai, G Porciello; 2) Divisione di Reumatologia, Ospedale San Camillo de Lellis, Roma, Italy: GD Sebastiani, G Minisola; 3) II Cattedra di Reumatologia, Dipartimento di Scienze Mediche, Centro Malattie Reumatiche Sistemiche, Università di Cagliari, Cagliari, Italy: A Mathieu, G Passiu, G Sanna, A Cauli; 4) Laboratorio di Immunologia Cellulare e Immunogenetica, Istituto di higher prevalence of SLE in certain ethnic groups, like African Americans and some Native Americans (18); and 4) studies of murine SLE showing that some strains invariably develop the disease $(23,24)$.

In humans, several genes contribute to lupus susceptibility. Their identification has been complicated by the fact that SLE is a heterogeneous disease, both clinically and immunologically (3); in addition, many of the susceptibility genes differ across the various populations (27), and it is well recognized that genetic

Medicina Interna, Malattie Infettive e Immunopatologia, Università di Milano IRCCS, Milano, Italy: R Scorza; 5) Autoimmune Diseases Research Unit, Servei de Medicina Interna General, Hospital Clinic, Barcelona, Spain: J Font, R Cervera, M Ingelmo; 6) Service de Médecine Interne Godeau, CHU PitiéSalpetrière, Paris, France: J-C Piette; 7) Service de Rhumatologie, Cliniques Universitaires Saint-Luc, Université Catholique de Louvain, Bruxelles, Belgium: F Houssiau; 8) Department of Immunology and Histocompatibility, Evangelismos Hospital, Athens, Greece: C Papasteriades, K Boki, N Nicolopoulou; 9) 2nd Department of Medicine, Center for Rheumatic Diseases, Lainz Hospital, Vienna, Austria: JS Smolen; 10) Servicio de Medicina Interna \& Section de Reumatologia, Hospital Clinico Universitario, Malaga, Spain: A Fenandez-Nebro, M de Haro-Liger, M Abarca-Costalago, J Rodriguez-Andreu; 11) Unidad de Enfermedades Autoinmunitarias Sistemicas, Servicio de Medicina Interna \& Servicio de Nefrologia, Hospital Regional Carlos Haya, Malaga, Spain: E de Ramon Garrido, MT Camps Garcia, MA Frutos Sanz; 12) Department of Connective Tissue Diseases, Institute of Rheumatology, University of Warsaw, Poland: A Jedryka-Goral, H Maldykowa, H Chwalinska-Sadowska; 13) $D i$ partimento di Genetica Medica, Istituto di Clinica Medica, Università di Cagliari, Cagliari, Italy: L Contu, C Carcassi; 14) Laboratorio di Immunogenetica, Centro di Biotecnologie Avanzate, Genova, Italy: GB Ferrara; 15) Dipartimento di Biologia Molecolare, Unità di Immunochimica, Università di Siena, Siena, Italy: L Bracci; 16) Istituto di Scienze Neurologiche, Università di Siena, Siena, Italy: P Annunziata. Other participants: Istituto Dermopatico dell'Immacolata IDI-IRCCS, Roma, Italy: P Puddu, O De Pità, C Girardelli.

Address reprint requests to: Prof. Mauro Galeazzi, Institute of Rheumatology, Policlinico "Le Scotte," Viale Bracci, 53100 Siena, Italy. Fax: 39-0-577-40450. 
predisposition is linked to autoantibody repertoires and to clinical subsets of disease $(9,20,31)$.

Many studies have focused on human leukocyte antigen (HLA) genes, mainly because they are involved in immune recognition and response, even if genetic susceptibility to SLE is in part located outside the short arm of the sixth chromosome $(13,22$, $30,33,35,36$ ). Studies performed by genomic scan of multiplex lupus families confirm the pathogenetic role of the HLA system in this disease (19).

We decided to approach the problem of HLA-SLE association in a large sample of patients, all of Caucasian origin, to enable study of homogeneous subsets defined clinically and serologically. In this paper, we present the results of an immunogenetic study conducted in a large series of European SLE patients. Our objective was to determine the HLA class II allele association with SLE and its main clinical and autoantibody subsets.

\section{Patients and Methods}

Five hundred seventy-seven patients with SLE $(91.2 \%$ female, $8.8 \%$ male; female:male ratio $=10: 1$ ), fulfilling 4 or more of the American Rheumatism Association (ARA) 1982 revised criteria for the classification of the disease (32), coming from 11 university hospitals of 7 European countries, were enrolled consecutively. Mean age of these patients was $37.9 \pm 13.1$ years (range, $13-79 \mathrm{yr}$ ). Mean age at the onset of the disease was $29.5 \pm 12.5$ years (range, 4-77 yr). Mean disease duration was $8.2 \pm 3.1$ years (range, $1-24$ yr). To avoid regional biases, each center was asked to contribute 60 patients, with the only exception the 2 centers in Malaga, in southern Spain, that were asked to give 30 patients each. Results were available for 577 patients, whose regional distribution is depicted in Table 1.

Each of the centers recorded the clinical characteristics of the patients, including the past medical history and a complete physical examination, using specific protocol forms, and collected blood and serum samples for the immunogenetic and serologic studies. All participating centers have substantial experience in

TABLE 1. Regional distribution of 577 European patients with systemic lupus erythematosus

\begin{tabular}{lcc}
\hline Country/Region & Center* & No. of Patients \\
\hline Belgium & 7 & 60 \\
France & 6 & 60 \\
Greece & 8 & 58 \\
Southern Spain & 10 & 27 \\
Southern Spain & 11 & 37 \\
Catalonia, Spain & 5 & 60 \\
Poland & 12 & 60 \\
Northern Italy & 4 & 60 \\
Central/southern Italy & 2 & 60 \\
Sardinia, Italy & 3 & 60 \\
Austria & 9 & 35
\end{tabular}

*For the center reference number see list of the centers participating in this study (European Concerted Action on the Immunogenetics of SLE) in footnote on first page of article. the management of patients with SLE. Nevertheless, in order to minimize the possible interobserver bias, the definition of the clinical features included in the protocol forms was discussed by all participating physicians on several occasions. (For a precise definition of the clinical features, see references 5 and 29.)

Blood and serum samples were taken from patients at the time clinical information was collected and were stored at $-80^{\circ} \mathrm{C}$. Subsequently, they were transported in dry ice to the respective laboratories by the researchers of the clinical centers.

HLA class II typing was done at the following 3 laboratories, with the same methodology: 1) Department of Medical Genetics, Institute of Clinica Medica, University of Cagliari, Italy; 2) Immunogenetics Laboratory, National Institute for Cancer Research, Genova, Italy; 3) Laboratory of Cellular Immunology and Immunogenetics, Institute of Internal Medicine, Infectious Diseases and Immunopathology, University of Milano, Italy. To guarantee quality control of the DNA typing tests and interlaboratory procedural uniformity, there was exchange of personnel as well as of biologic material (blood samples, genetic probes) between the 3 laboratories where the tests were performed. In each patient, the following HLA loci were studied: DRB1, DRB3, DRB4, DRB5, DQA1, DQB1.

The frequency of HLA alleles in patients with SLE was compared with the frequency in a healthy Caucasian population, matched for ethnic origin, taken from the 12th International Histocompatibility Workshop (IHW) (11). Results of HLA class II allele typing of a healthy Polish population were from Jungerman et al (16).

Various serologic tests were performed, including the detection of autoantibodies that are more commonly found with SLE. Each serologic test was performed in the same laboratory for all patients (Institute of Rheumatology, University of Siena, Italy). Centralized data handling, computing, and statistical analysis took place at the Rheumatology Division, San Camillo Hospital, Rome, Italy. The data were transferred into a computerized database program (DBASE III PLUS) and were analyzed using the Statistical Package for Social Sciences (SPSS) program.

The study, approved by the Human Experimental Committee of each participating hospital, was carried out according to the principles of the Declaration of Helsinki. Informed consent was obtained from all patients.

\section{Autoantibody detection}

Antinuclear antibodies (ANA) were determined by indirect immunofluorescence using Hep-2 cells as substrate. Anti-dsDNA antibodies were determined by indirect immunofluorescence with Crithidia luciliae as substrate. Precipitating antibodies to extractable nuclear antigens, including Ro (SS-A), La (SS-B), U1-RNP, Sm, Jo1, SCL70, PCNA, were detected by double immunodiffusion and counterimmunoelectrophoresis using calf and rabbit thymus and human spleen extracts, as previously described $(10,20)$.

Other autoantibodies, such as anticardiolipin antibodies, anti$\beta 2$ glycoprotein I antibodies, antineutrophil cytoplasmic antibodies, and antiganglioside antibodies, were also determined. Results of their correlation with clinical manifestation and HLA class II alleles have been published separately (7-10).

\section{HLA typing}

Molecular typing of HLA-DRB1, DRB3, DRB4, DRB5, DQA1 and DQB1 was performed according to the 11th IHW reference protocol (17) with minor variations. 
DNA was extracted from peripheral blood mononuclear cells using a standard phenol/chloroform technique. HLA-DRB, DQA1, DQB1 alleles were typed by the polymerase chain reaction-sequence specific oligonucleotide probes (PCR-SSOP) method, carried out using digoxigenin (DIG)-labeled probes. The primers and the oligonucleotide probes used were those validated by the 11th IHW. Briefly, the second exon of each gene is specifically PCR amplified; the amplified fragment is immobilized on a nylon positively-charged membrane (Zeta-Probe blotting membrane, Bio-Rad, Hercules, CA) and hybridized with sequence-specific probes previously 3 '-end labeled with DIG-ddUTP using terminal-transferase (Boehringer Mannheim Gmbh, Germany). An anti-DIG-alkaline phosphatase conjugate (Fab fragments) (Boehringer Mannheim Gmbh) is bound to the DIGlabeled hybrids; incubation with CSPD (Tropix, Bedford, MA) substrate allows the chemiluminescent detection of the hybrids, by exposing the membranes to a X-Omat AR autoradiography film (Eastman Kodak, Rochester, NY).

\section{Statistical analysis}

Frequencies of HLA alleles were compared among the various groups using conventional chi-square analysis with the Yates correction or, when appropriate, the Fisher exact test (2-tailed). The $\mathrm{p}$ value for HLA frequency differences was corrected (pc) for the number of comparisons. A p value equal to or less than 0.05 was taken as significant. An odds ratio (OR) was calculated, when the p value was significant, by using $2 \times 2$ contingency tables. When the value of a cell in the $2 \times 2$ table was 0 , relative risk (RR) was calculated by Haldane's modification of Woolf's method (12):

$$
R R=\frac{(a+1 / 2)}{(b+1 / 2)} \frac{(d+1 / 2)}{(c+1 / 2)}
$$

This statistical analysis was performed by means of the SPSS program using the information stored in the database program.

\section{Results}

Frequency of HLA class II alleles in patients and in healthy controls

As expected, frequency of HLA-DRB $1 * 03$ was significantly higher in SLE patients compared with healthy controls (35.2 vs 19.4, $\mathrm{p}<10^{-6}, \mathrm{pc}=1.3 \times$ $10^{-5}, \mathrm{OR}=2.2,95 \%$ CI [confidence intervals] $=$ 1.8-2.9) (Table 2). In addition, DRB1*15 and DRB1*16 (DR2) were significantly associated with SLE (respectively, 27.7 vs $19.4, \mathrm{p}=0.003, \mathrm{pc}=0.04, \mathrm{OR}=1.6$, $95 \% \mathrm{CI}=1.2-2$, and 14.4 vs $10.5, \mathrm{p}=0.03, \mathrm{pc}=$ not significant $[\mathrm{NS}], \mathrm{OR}=1.4,95 \% \mathrm{CI}=1.1-2)$. On the contrary, DRB1*01, DRB1*04, and DRB1*11 (DR5) showed negative association with SLE. Alleles at the DRB3 locus were not associated with the disease.

Among the alleles at the DQA1 locus, only DQA1*0102 showed a positive association with SLE (42.6 vs $32.8, \mathrm{p}=2 \times 10^{-4}, \mathrm{pc}=0.006, \mathrm{OR}=1.5,95 \%$ $\mathrm{CI}=1.2-1.9)$, whereas DQA1*0101 and DQA1*03 were negatively associated (Table 3).

Some alleles at the DQB1 locus were found with significantly increased frequency in patients with SLE compared with healthy controls. They were $\mathrm{DQB} 1 * 0502(17.8$ vs $11.6, \mathrm{p}=0.001, \mathrm{pc}=0.03, \mathrm{OR}=$ $1.6,95 \% \mathrm{CI}=1.2-2.2), \mathrm{DQB} 1 * 0602(20.7$ vs $15.1, \mathrm{p}=$ $0.008, \mathrm{pc}=\mathrm{NS}, \mathrm{OR}=1.5,95 \% \mathrm{CI}=1.1-1.9)$, DQB1*0201 (52.7 vs 39.7, $\mathrm{p}=2 \times 10^{-6}, \mathrm{pc}=5.6 \times$ $\left.10^{-5}, \mathrm{OR}=1.7,95 \% \mathrm{CI}=1.3-2.1\right), \mathrm{DQB} 1 * 0303(5.8 \mathrm{vs}$ $3.4, \mathrm{p}=0.05, \mathrm{pc}=\mathrm{NS}, \mathrm{OR}=1.7,95 \% \mathrm{CI}=1-2.9)$, $\mathrm{DQB} 1 * 0304(1.9$ vs $0.4, \mathrm{p}=0.02, \mathrm{pc}=\mathrm{NS}, \mathrm{OR}=4.3$,

TABLE 2. Phenotypic frequency of HLA-DRB1 and DRB3 alleles in patients with SLE and in healthy controls

\begin{tabular}{|c|c|c|c|c|c|c|}
\hline & $\begin{array}{c}\text { Patients } \\
\text { with SLE }\end{array}$ & Controls & p Value & $\underset{(p \times 13)}{p c}$ & $* * \mathrm{OR}$ & $95 \% \mathrm{CI}$ \\
\hline DRB1 & $(\mathrm{n}=534)$ & $(\mathrm{n}=958)$ & & & & \\
\hline$* 01$ & 14.4 & 22.3 & .003 & .04 & .6 & $.4-.8$ \\
\hline$* 15$ & 27.7 & 19.4 & .003 & .04 & 1.6 & $1.2-2$ \\
\hline$* 16$ & 14.4 & 10.5 & .03 & NS & 1.4 & $1.1-2$ \\
\hline$* 03$ & 35.2 & 19.4 & $<10^{-6}$ & $1.3 \times 10^{-5}$ & 2.2 & $1.8-2.9$ \\
\hline$* 04$ & 14.6 & 21.3 & .002 & .03 & .6 & $.5-.8$ \\
\hline$* 11$ & 20.2 & 27.3 & .003 & .04 & .7 & $.5-.9$ \\
\hline$* 12$ & 3.4 & 1.9 & NS & & & \\
\hline$* 13$ & 20.4 & 18.3 & NS & & & \\
\hline$* 14$ & 5.4 & 6.3 & NS & & & \\
\hline$* 07$ & 22.8 & 23.3 & NS & & & \\
\hline$* 08$ & 5.6 & 5.3 & NS & & & \\
\hline$* 09$ & 1.7 & 2 & NS & & & \\
\hline$* 10$ & 2.2 & 2.3 & NS & & & \\
\hline DRB3 & $(\mathrm{n}=376)$ & $(\mathrm{n}=670)$ & & & & \\
\hline$* 01$ & 44.2 & 38.2 & NS & & & \\
\hline$* 02$ & 57.5 & 61.1 & NS & & & \\
\hline$* 03$ & 11.2 & 15.3 & NS & & & \\
\hline
\end{tabular}

Abbreviations: SLE $=$ systemic lupus erythematosus; $p c=$ probability corrected for multiple comparison; $\mathrm{OR}=$ odds ratio; $\mathrm{CI}=$ confidence interval; $\mathrm{NS}=$ not significant. 
TABLE 3. Phenotypic frequency of HLA-DQA1 and DQB1 alleles in patients with SLE and in healthy controls

\begin{tabular}{|c|c|c|c|c|c|c|}
\hline & $\begin{array}{l}\text { Patients } \\
\text { with SLE }\end{array}$ & Controls & $\mathrm{p}$ Value & $\begin{array}{c}\mathrm{pc} \\
(\mathrm{p} \times 28)\end{array}$ & $\mathrm{OR}$ & $95 \%$ CI \\
\hline DQA1 & $(\mathrm{n}=535)$ & $(\mathrm{n}=900)$ & & & & \\
\hline$* 0101$ & 17.2 & 29 & $<10^{-6}$ & $2.8 \times 10^{-5}$ & .5 & $.4-.7$ \\
\hline$* 0102$ & 42.6 & 32.8 & $2 \times 10^{-4}$ & .006 & 1.5 & $1.2-1.9$ \\
\hline *0103 & 12 & 14.2 & NS & & & \\
\hline$* 0104$ & 4.9 & .8 & $\mathrm{NS}$ & & & \\
\hline *0201 & 22.8 & 22.8 & NS & & & \\
\hline$* 03$ & 16.6 & 23.7 & .002 & $\mathrm{NS}$ & .6 & $.5-.8$ \\
\hline$* 0401$ & 5.6 & 4.6 & NS & & & \\
\hline$* 0501$ & 53.5 & 50.6 & NS & & & \\
\hline$* 06$ & 3.6 & .6 & NS & & & \\
\hline DQB1 & $(\mathrm{n}=535)$ & $(\mathrm{n}=900)$ & & & & \\
\hline$* 0501$ & 16.4 & 25 & $2 \times 10^{-4}$ & .006 & .6 & $.4-.8$ \\
\hline *0502 & 17.8 & 11.6 & .001 & .03 & 1.6 & $1.2-2.2$ \\
\hline$* 0503$ & 5 & 3.7 & NS & & & \\
\hline$* 0504$ & .4 & .1 & NS & & & \\
\hline *0601 & 3.6 & 4.2 & NS & & & \\
\hline *0602 & 20.7 & 15.1 & .008 & NS & 1.5 & $1.1-1.9$ \\
\hline *0603 & 9.3 & 10.1 & NS & & & \\
\hline$* 0604$ & 5.8 & 5.3 & NS & & & \\
\hline *0605 & .4 & .8 & $\mathrm{NS}$ & & & \\
\hline *0609 & .9 & .1 & NS & & & \\
\hline *0201 & 52.7 & 39.7 & $2 \times 10^{-6}$ & $5.6 \times 10^{-5}$ & 1.7 & $1.3-2.1$ \\
\hline *0301 & 28.2 & 38.6 & $9 \times 10^{-5}$ & .002 & .6 & $.5-.8$ \\
\hline *0302 & 8.8 & 14.2 & .003 & NS & .6 & $.4-8$ \\
\hline *0303 & 5.8 & 3.4 & .047 & NS & 1.7 & $1-2.9$ \\
\hline *0304 & 1.9 & 0.4 & .02 & NS & 4.3 & $1.2-16.2$ \\
\hline *0305 & .2 & .1 & NS & & & \\
\hline *0401 & .9 & 1.2 & NS & & & \\
\hline *0402 & 4.3 & 4 & NS & & & \\
\hline$* 08$ & 0.9 & 0.5 & NS & & & \\
\hline
\end{tabular}

$95 \%$ CI $=1.2-16.2$ ). Conversely, DQB1*0501, DQB1*0301, and DQB1*0302 showed a negative association with SLE (see Table 3).

Frequency of autoantibodies in lupus patients and correlation with HLA class II alleles

Frequencies of those autoantibodies of interest for this paper are depicted in Table 4. They are in keeping with the findings in previous studies. With the exception of anti-dsDNA ( $\mathrm{pc}=0.001)$, the frequencies of all other autoantibodies were not statistically different among the various centers. On the other hand, the frequency of anti-dsDNA in every patient was quite variable with time, depending mainly on the disease activity and therapy.

As already known, anti-Ro was overrepresented in haplotypes containing DR3 (36.6 in patients DRB1*03 positive vs 19 in their negative counterparts, $\mathrm{p}=2 \times 10^{-5}, \mathrm{pc}=3 \times 10^{-4}, \mathrm{OR}=2.4,95 \% \mathrm{CI}$ $=1.6-3.7)$, as well as anti-La (13.1 vs 2.7, $\mathrm{p}=1 \times$ $\left.10^{-5}, \mathrm{pc}=1 \times 10^{-4}, \mathrm{OR}=5.5,95 \% \mathrm{CI}=2.5-12.1\right)$
(Table 5). Both these autoantibodies were also strongly associated with DQB1*0201 (DQw2), which is in strong linkage disequilibrium with $\mathrm{DRB} 1 * 03$, and, obviously, showed a strong association with haplotypes containing $\mathrm{DRB} 1 * 03$ and $\mathrm{DQB} 1 * 0201$. Anti-Ro, but not anti-La, was also associated with DQB1*0502 (DQw1), and with the haplotype DR2/

TABLE 4. Relative frequency of autoantibodies in patients with SLE

\begin{tabular}{lc}
\hline Specificity & Frequency \\
\hline dsDNA & 56.2 \\
Ro & 25.2 \\
La & 6.3 \\
Sm & 7.2 \\
U1-RNP & 18.5 \\
Jo1 & 0.2 \\
SCL70 & 0.2 \\
PCNA & 0.9 \\
\hline
\end{tabular}

Abbreviations: ds-DNA $=$ double-strand DNA; $\mathrm{Sm}=$ Smith; U1$\mathrm{RNP}=$ U1-ribo-nuclear-proteins; SCL70 = sclero 70; PCNA = proliferating cells nuclear antigens. 
TABLE 5. Relative frequency of significantly associated autoantibodies in patients positive and negative for the various HLA alleles/haplotypes

\begin{tabular}{|c|c|c|c|c|c|c|c|}
\hline HLA & Anti-dsDNA & Anti-Ro & Anti-La & p Value & pc & OR & $95 \% \mathrm{CI}$ \\
\hline$\overline{\mathrm{DRB} 1 * 03}$ & & 36.6 vs 19 & & $2 \times 10^{-5}$ & $3 \times 10^{-4}$ & 2.4 & $1.6-3.7$ \\
\hline DRB1*03 & & & 13.1 vs 2.7 & $1 \times 10^{-5}$ & $1 \times 10^{-4}$ & 5.5 & $2.5-12.1$ \\
\hline DRB1*15 & 66.2 vs 52.2 & & & 0.008 & NS & 1.8 & $1.2-2.7$ \\
\hline DQA1*0102 & 63.6 vs 50.4 & & & 0.004 & NS & 1.7 & $1.2-2.5$ \\
\hline DQA $1 * 0501$ & & & 8.7 vs 3.7 & 0.03 & NS & 2.5 & $1.1-5.4$ \\
\hline DQA1*0601 & & 55.6 vs 24.2 & & 0.006 & NS & 3.9 & $1.5-10.2$ \\
\hline $\mathrm{DQB} 1 * 0201$ & & 33.5 vs 18.1 & & $8 \times 10^{-5}$ & 0.002 & 2.3 & $1.5-3.4$ \\
\hline DQB1*0201 & & & 10.7 vs 2.5 & $3 \times 10^{-4}$ & 0.008 & 4.6 & $2-10.9$ \\
\hline $\mathrm{DQB1} * 0502$ & & 37.4 vs 22.7 & & 0.005 & NS & 2 & $1.3-3-3$ \\
\hline $\mathrm{DQB1} * 0602$ & 66 vs 53.5 & & & 0.03 & NS & 1.7 & $1.1-2.7$ \\
\hline DRB1*03/DQB1*0201 & & 36.7 vs 19.2 & & $2 \times 10^{-5}$ & $3 \times 10^{-4}$ & 2.4 & $1.6-3.7$ \\
\hline $\mathrm{DRB} 1 * 03 / \mathrm{DQB} 1 * 0201$ & & & 13.3 vs 2.7 & $1 \times 10^{-5}$ & $1 \times 10^{-4}$ & 5.6 & $2.6-12.4$ \\
\hline DR2/DQB1*0502 & & 37.6 vs 22.8 & & 0.006 & NS & 2 & $1.2-3.3$ \\
\hline
\end{tabular}

Abbreviations: See previous tables.

DQB1*0502. It was not associated with DR2 (DRB1*15, DRB1*16). Anti-dsDNA was associated with $\mathrm{DRB} 1 * 15$ (66.2 vs 52.2, p $=0.008, \mathrm{pc}=\mathrm{NS}$, $\mathrm{OR}=1.8,95 \% \mathrm{CI}=1.2-2.7$ ), DQA1 0102 (63.6 vs 50.4, $\mathrm{p}=0.004, \mathrm{pc}=\mathrm{NS}, \mathrm{OR}=1.7,95 \% \mathrm{CI}=1.2-2.5)$, and DQB1*0602 (66 vs 53.5, $\mathrm{p}=0.03, \mathrm{pc}=\mathrm{NS}, \mathrm{OR}=1.7$, $95 \% \mathrm{CI}=1.1-2.7)$.

Anti-Ro showed negative association with DRB1*01 (11 vs 27.6, p = 0.004, pc $=\mathrm{NS}, \mathrm{OR}=0.3$, $95 \% \mathrm{CI}=0.1-0.7), \mathrm{DRB} 1 * 14$ (3.6 vs $26.5, \mathrm{p}=0.01$, $\mathrm{pc}=\mathrm{NS}, \mathrm{OR}=0.1,95 \% \mathrm{CI}=0.01-0.8), \mathrm{DQA} 1 * 0101$ (10.2 vs 28.3, $\mathrm{p}=6 \times 10^{-4}, \mathrm{pc}=0.02, \mathrm{OR}=0.3,95 \%$ $\mathrm{CI}=0.1-0.6), \mathrm{DQB} 1 * 0501(10.7$ vs $28, \mathrm{p}=0.001$, $\mathrm{pc}=0.03, \mathrm{OR}=0.3,95 \% \mathrm{CI}=0.1-0.6)$, and DQB1*0503 (0 vs 26.5, $\mathrm{p}=0.006, \mathrm{pc}=\mathrm{NS}, \mathrm{OR}=0.7$, $95 \% \mathrm{CI}=0.6-0.8)$. Anti-U1-RNP was negatively associated with DRB1*03 (12 vs $21.4, \mathrm{p}=0.01$, pc $=\mathrm{NS}$, $\mathrm{OR}=0.5,95 \% \mathrm{CI}=0.3-0.8)$, and DQA $1 * 0501$ (13 vs $24, \mathrm{p}=0.002, \mathrm{pc}=\mathrm{NS}, \mathrm{OR}=0.5,95 \% \mathrm{CI}=0.3-$ $0.7)$. Anti-nDNA was negatively associated with DQB1*0301 (48.2 vs 59.1, p = 0.04, pc $=\mathrm{NS}, \mathrm{OR}=0.6$, $95 \% \mathrm{CI}=0.4-0.9)$. The other autoantibodies showed no association with HLA class II alleles.

\section{Correlation of clinical manifestations with HLA class II alleles and with autoantibodies}

Frequency of clinical manifestation was compared among the 11 centers. The following clinical manifestations showed a significantly different frequency: leukopenia $\left(\mathrm{pc}=6 \times 10^{-4}\right.$, ranging from $20 \%$ in patients coming from Austria to $80 \%$ in patients from Catalonia, Spain), lymphopenia ( $\mathrm{pc}=6 \times 10^{-4}$, ranging from $10 \%$ in patients from central/southern Italy to $85 \%$ in French patients), lymphadenopathy (pc = $6 \times 10^{-4}$, ranging from about $37 \%$ in French and Greek patients to about 20\% in patients in all other centers), central nervous system involvement (pc = $6 \times 10^{-4}$, ranging from about $69 \%$ in patients from
France and Poland to $15 \%$ in those from northern Italy), livedo reticularis ( $\mathrm{pc}=6 \times 10^{-4}$, ranging from about $43 \%$ in patients from Poland and Greece to about $15 \%$ in those from the other centers). The association between these clinical manifestations and HLA alleles could be due to environmental factors or might be due to regional biases regarding diagnosis, and has to be considered cautiously. All other clinical manifestations showed a similar frequency across the 11 centers.

Some HLA class II alleles were associated with clinical manifestations of SLE (Table 6), perhaps due to their association with autoantibodies. Indeed, DRB1*03 was associated with pleuritis, lung involvement, renal involvement, and psychosis. DRB1*16 carried a higher risk for renal involvement, discoid lupus, and lymphadenopathy. DQA1*0101 was associated with lymphadenopathy, and DQA1*03 with lung involvement, lymphopenia, and hemolytic anemia. DQB1*0201 (DQw2) was associated with leukopenia, digital skin vasculitis, and pleuritis, while DQB1*0502 (DQw1) was associated with renal involvement, discoid lupus, and livedo reticularis.

Conversely, several HLA class II alleles were negatively associated with clinical manifestations of SLE (Table 7). DRB1*01 showed negative associations with renal and CNS involvement; DRB1*11 was negatively associated with renal disease and lymphopenia; and DRB1*14 was negatively associated with leukopenia, lymphopenia, and digital skin vasculitis. Concerning the DQ locus, DQA1*0101 showed negative associations with cardiac and renal disease, DQA1*0102 with CNS involvement, DQB1*0301 with arthritis and renal involvement, DQB1*0501 with renal involvement, and DQB1*0503 with leukopenia.

Some of these clinical manifestations were associated with the presence of autoantibodies. Namely, anti-Ro was associated with pleuritis (39.9 in patients anti-Ro positive vs 22.8 in those anti-Ro negative, $\mathrm{p}=$ 
TABLE 6. Relative frequency of major clinical manifestations in patients positive and negative for the various HLA alleles (positive associations)

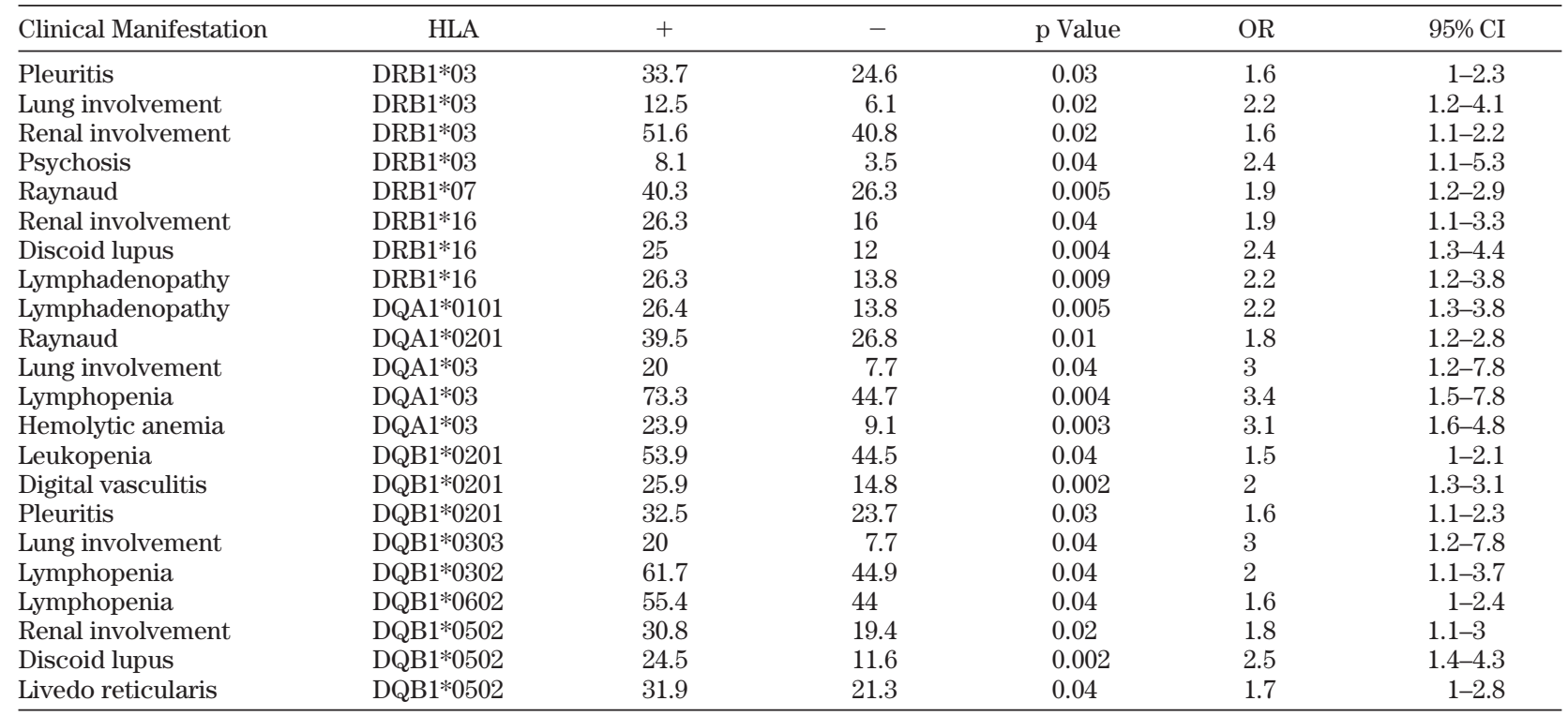

Abbreviations: See previous tables.

$\left.1 \times 10^{-4}, \mathrm{OR}=2.2,95 \% \mathrm{CI}=1.5-3-3\right)$, and with lung involvement (15.4 vs $5.2, \mathrm{p}=2 \times 10^{-4}, \mathrm{OR}=3.3,95 \%$ $\mathrm{CI}=1.8-6.2)$. Anti-La was associated with pleuritis (44.4 vs $25.9, \mathrm{p}=0.03, \mathrm{OR}=2.3,95 \% \mathrm{CI}=1.15-4.5)$, and showed negative association with renal disease (2.8 vs $18.4, \mathrm{p}=0.03, \mathrm{OR}=0.1,95 \% \mathrm{CI}=0.02-0-9$ ).

Although found in the context of SLE, other clinical manifestations that are more typical of the antiphospholipid syndrome are discussed in another paper (7).

\section{Discussion}

Multiple loci contribute to SLE, and disease pathogenesis is expressed as a complex genetic interaction that is undoubtedly influenced by environmental factors.

Genetic studies are complicated because the disease is polygenic, with susceptibility derived from a number of genes with relatively small effects (30), possibly interacting (22). Genetic studies in SLE are

TABLE 7. Relative frequency of major clinical manifestations in patients positive and negative for the various HLA alleles (negative associations)

\begin{tabular}{|c|c|c|c|c|c|c|}
\hline Clinical Manifestation & HLA & + & - & $\mathrm{p}$ Value & OR & $95 \% \mathrm{CI}$ \\
\hline Renal involvement & DRB $1 * 01$ & 10.5 & 23.3 & 0.02 & 0.4 & $0.2-0.8$ \\
\hline CNS involvement & DRB1*01 & 1.3 & 8.6 & 0.05 & 0.1 & $0.01-0.9$ \\
\hline Renal involvement & DRB1*11 & 28.3 & 43.9 & 0.005 & 0.5 & $0.3-0.8$ \\
\hline Lymphopenia & $\mathrm{DRB} 1 * 11$ & 34.9 & 49.2 & 0.01 & 0.5 & $0.4-0.9$ \\
\hline Leukopenia & DRB1*14 & 17.9 & 50.5 & 0.001 & 0.2 & $0.08-0.6$ \\
\hline Lymphopenia & $\mathrm{DRB} 1 * 14$ & 2.5 & 47.5 & 0.03 & 0.4 & $0.01-0.9$ \\
\hline Digital vasculitis & DRB1*14 & 3.6 & 20.8 & 0.05 & 0.1 & $0.02-0.9$ \\
\hline Cardiac involvement & DQA1*0101 & 2.2 & 10.1 & 0.03 & 0.2 & $0.05-0.8$ \\
\hline Renal involvement & DQA $1 * 0101$ & 13.2 & 23.2 & 0.05 & 0.5 & $0.3-0.9$ \\
\hline CNS involvement & DQA1*0102 & 39.4 & 48.8 & 0.04 & 0.7 & $0.5-0.9$ \\
\hline Arthritis & DQB1*0301 & 67.6 & 78.1 & 0.02 & 0.6 & $0.4-0.9$ \\
\hline Renal involvement & DQB1*0301 & 33.8 & 48.5 & 0.003 & 0.5 & $0.4-0.8$ \\
\hline Renal involvement & $\mathrm{DQB} 1 * 0501$ & 11.5 & 23.4 & 0.02 & 0.4 & $0.2-0.8$ \\
\hline Leukopenia & DQB1*0503 & 15.4 & 50.5 & 0.001 & 0.2 & $0.06-0.5$ \\
\hline
\end{tabular}

Abbreviations: See previous tables. 
TABLE 8. HLA-DR, DQ associations with SLE in different ethnic groups

\begin{tabular}{lclr}
\hline Ethnicity & $\begin{array}{c}\text { No. of } \\
\text { Patients }\end{array}$ & \multicolumn{1}{c}{ HLA Associations } & Ref. \\
\hline Netherlands & 99 & DRB1*03 & 28 \\
$\begin{array}{l}\text { Mexico } \\
\text { (Mestizo) }\end{array}$ & 58 & $\begin{array}{l}\text { DR3, DQA1*0501, DQB1*0201 } \\
\text { DR1, DQA1*0101, DQB1*0501 }\end{array}$ & 4 \\
Spain & 85 & $\begin{array}{l}\text { DR3 } \\
\text { DQA1*0501 }\end{array}$ \\
Greece & 46 & $\begin{array}{l}\text { DRB1*1501, DRB1*1601 and } \\
\text { DRB1*0701 }\end{array}$ & 34 \\
\hline
\end{tabular}

${ }^{\circ}$ Haplotype.

difficult also because SLE is heterogeneous, divisible in several clinical and immunologic subsets, each with its own genetic background. Furthermore, genes predisposing to SLE may vary according to the ethnic origin of the patient.

Studies, including association and family studies, have confirmed the linkage of the disease to the MHC region in humans (19). It also has been suggested that certain MHC haplotypes show stronger association with autoantibodies in SLE than with the disease itself (2).

Studies of the association between HLA class II alleles and SLE, and between HLA and serologic subtypes of the disease, were reviewed in depth by Reveille in 1999 (26), and we refer the reader to that paper for reference consultation. In Table 8 and Table 9 we have listed the most important associations described by other authors starting in 1998 (4, 6, 21, 25, $27,28,34)$. In summary, these studies found that HLADR3 was associated with Caucasian SLE patients in North America, the United Kingdom, Australia, Spain, Italy, Scandinavia, Switzerland, Austria, and, more recently, also in Germany (27) and the Netherlands (28), while in Greece the most significant association was with HLA-DR5 (DR11), and in northern India, with HLA-DR4. On the other hand the HLA-DR2 allele DRB1*1501 was associated with SLE in Caucasians and Asian groups including Japanese, Chinese, and Koreans, while in black patients the HLA-DR2 association was with the DRB1*1503 allele. In MexicanAmericans SLE was found to be associated with
HLA-DR3, and in both Mexican and Peruvian mestizos, with HLA-DR8. More recently (27) SLE was found to be associated with HLA-DQA1*0501 and DQB1*0201 in Caucasian patients and with HLADQB1*0602 in African Americans. In addition, in Mexican mestizo patients, an association has been found with HLA-DR3, DQA1*0501, DQB1*0201, and with HLA-DR1, DQA1*0101, and DQB1*0501 haplotypes (4). In Spanish patients an association of SLE with both HLA-DR3 and HLA-DQA1*0501 has been found (21), while in Greek SLE patients, associations with HLA-DRB1*1501, *1601, and *0701 have been described (34).

Concerning the HLA-DR and DQ genes and autoantibody subsets of SLE, associations (26) have been found between anti-dsDNA antibodies and DR2 (DRB1*1501) and DR3 and their respective linked HLA-DQ alleles (DQA1*0102, DQB1*0602 and DQA1*0501, DQB1*0201), as well as, in those lacking these alleles, DQB $1 * 0302$. An association of antidsDNA antibodies with HLA-DR15 and Dw2 in French Canadian SLE patients has been reported (25).

Anti-Ro and anti-La antibodies have been found to be associated with HLA-DR2 and DR3 and with the concomitant presence of DQ1 and DQ2. Furthermore, studies from 2 different European centers have implicated the HLA-B8-C4A*Q0-DRB1*0301DQA1*0501-DQB1*0201 haplotype in susceptibility to anti-Ro/La autoantibody responses in Caucasians. In Japanese patients, the only association reported has been with HLA-DR8. The concomitant production of anti-Ro and anti-La antibodies has been found to be associated with HLA-DQA $* 0501$ and DQB1*0201 alleles in Spanish patients (21). More recently, an association has been found in Italy between anti-Ro/La response and HLA-DRB1*03011, DQA1*0501, and DQB1*0201 haplotype (6).

Anti-U1-RNP antibodies have been found to be associated in both Japanese and Caucasians with HLADR4 and DQw3 (the serologic group comprising HLA-DQB1*0301, *0302, and *0303). Subsequent studies, using oligotyping and DNA sequencing, have implicated both HLA-DRB1 and HLA-DQB1 allelesspecifically shared epitopes between HLA-DR2 and DR4 and HLA-DQB1*0302, linked to HLA-DR4-as

TABLE 9. HLA class II alleles and autoantibody subsets of SLE

\begin{tabular}{|c|c|c|c|c|}
\hline Autoantibody & Ethnicity & $\begin{array}{l}\text { No. of } \\
\text { Patients }\end{array}$ & HLA Associations & Ref. \\
\hline Anti-ds DNA & $\begin{array}{l}\text { Canada } \\
\text { (French) }\end{array}$ & 91 & DR15 and Dw2 & 25 \\
\hline Anti-Ro/La & Spain & 85 & DQA1*0501 and DQB1*0201 & 21 \\
\hline Anti-Ro/La & Italy & undefined & DRB $1 * 03011, \mathrm{DQA1} * 0501, \mathrm{DQB} 1 * 0201^{\circ}$ & 6 \\
\hline
\end{tabular}


well as other specific DQB1 alleles sharing specific epitopes with DQB1*0302 in both Caucasians and Japanese.

All studies mentioned above do have limitations. The studies often did not use homogeneous clinical criteria for patient assessment, and they used different laboratory methods for the detection of autoantibodies that cannot be compared. In addition the number of patients recruited is usually rather low.

Because of the above-mentioned considerations, we wanted to verify the characteristics of the association of SLE with HLA class II alleles in a large sample of European patients. In fact, the large sample size allowed us to divide patients into various subsets, defined according to clinical characteristics and autoantibody status, and the common origin of the patients allowed us to overcome the problem of ethnic influence on HLA-SLE association. On the other hand, results of our study may be hampered at least in part by the relatively high number of participating centers, because we can not rule out completely the influence of environmental factors and of biases regarding diagnosis. The results presented here suggest that the overall contribution of the MHC to the disease itself is much less than its contribution to certain types of autoantibodies (and, in turn, to related clinical manifestations).

In fact, we have already shown that particular HLA class II alleles (DRB1*04, DRB1*07, DQA1*0201, DQA1*0301, DQB1*0302), in the context of SLE, predispose to the production of antiphospholipid antibodies and, as a consequence, to the development of clinical manifestations related to the antiphospholipid syndrome (9). We have also found significant association between other HLA alleles and both antiganglioside antibodies and related clinical manifestations (7).

In this paper, we show that, in the same patient sample, other HLA class II alleles confer susceptibility for different autoantibodies and possibly related clinical manifestations. For instance, patients carrying the DRB1*03 allele and the closely linked DQB1*0201 allele show genetic predisposition to the production of autoantibodies to Ro, La, and to pulmonary involvement, pleuritis, and psychosis. Interestingly, a similar association between DQB1*0201 and anti-Ro/La antibodies has been previously described in a Spanish population. To our knowledge, we have found for the first time that patients carrying the DQB $1 * 0502$ allele, which is in linkage disequilibrium with DR2, are prone to develop anti-Ro antibodies without anti-La antibodies, renal disease, discoid lupus, and livedo reticularis, whereas the presence of anti-La antibodies might be protective for renal disease. The association of Raynaud phenomenon and DRB1*07 (never described before, to our knowledge) is probably a consequence of the association of this allele with antiphospholipid antibodies (9). DR2 (DRB1*15, DRB1*16) was associated with anti-dsDNA antibodies, confirming data previously described in Caucasian populations. It is noteworthy that we found for the first time, as far as we know, that DR2 haplotypes were also associated with renal disease, discoid lupus, and lymphadenopathy. DRB1*11 (DR5) appeared to protect against severe lupus, characterized by nephritis and lymphopenia, while SLE patients carrying DR1 showed a decreased risk for renal and CNS involvement, together with a decreased frequency of anti-Ro. Furthermore, DRB1*14 was associated with a decreased risk of having antiRo, and patients with this allele were less prone to develop digital skin vasculitis, leukopenia, and lymphopenia. The negative association of anti-dsDNA antibodies with DQB1*0301 could explain why patients with this allele had less renal disease.

Therefore, our results confirm that the role of HLA class II genes in SLE is to influence the production of the autoantibody repertoire and clinical manifestations, whereas the onset of SLE is more likely the consequence of the cooperation of many other nonHLA genes, interacting with appropriate external stimuli. Indeed, recent family studies showed that the genetic predisposition to SLE is only in minimal part located on the short arm of the sixth chromosome. Other regions of the human genome appear to be more important for SLE susceptibility, such as those located in chromosome 1, 2, 14, 16, and 20 (19). In addition, family studies show that different susceptibility loci are involved in the development of SLE in different ethnic populations, confirming the genetic heterogeneity of this disease.

In conclusion, our study of a large sample of Caucasian patients with lupus shows some new HLA clinical and serologic associations in SLE and reinforces the concept that this disease is genetically complex and that the role of MHC genes is mainly to predispose to particular serologic and clinical manifestations.

\section{Summary}

We conducted this study to determine the HLA class II allele associations in a large cohort of patients of homogeneous ethnic derivation with systemic lupus erythematosus (SLE). The large sample size allowed us to stratify patients according to their clinical and serologic characteristics. We studied 577 European Caucasian patients with SLE. Antinuclear antibodies (Hep-2 cells), anti-dsDNA antibodies (Crithidia luciliae), and antibodies to extractable nuclear antigens Ro (SS-A), La (SS-B), U1-RNP, Sm, Jo1, SCL70, and PCNA, were detected in all patients. Molecular typing of HLA-DRB1, DRB3, DQA1, and DQB1 loci was performed by the polymerase chain 
reaction-sequence specific oligonucleotide probes (PCR-SSOP) method.

We found a significantly increased frequency of DRB1*03, DRB1*15, DRB1*16, DQA1*0102, DQB1*0502, DQB1*0602, DQB1*0201, DQB1*0303, and DQB1*0304 in lupus patients as compared with healthy controls. In addition, DRB1*03 was associated with anti-Ro, anti-La, pleuritis, and involvement of lung, kidney, and central nervous system. DRB1*15 and DQB1*0602 were associated with antidsDNA antibodies; DQB1*0201 with anti-Ro and antiLa, leukopenia, digital skin vasculitis, and pleuritis; and DQB1*0502 was associated with anti-Ro, renal involvement, discoid lupus, and livedo reticularis.

In conclusion, our study shows some new HLA clinical and serologic associations in SLE and further confirms that the role of MHC genes is mainly to predispose to particular serologic and clinical manifestations of this disease.

\section{References}

1. Alarcon-Segovia D. The pathogenesis of immune dysregulation in systemic lupus erythematosus. A troika. J Rheumatol 11: 588-90, 1984.

2. Arnett FC. The genetics of human lupus. In: Wallace DJ, Hahn BH, eds. Dubois' lupus erythematosus. 5th ed. Philadelphia: Williams \& Wilkins, p 88, 1997.

3. Arnett FC. The genetics of human lupus. In: Wallace DJ, Hahn BH, eds. Dubois' lupus erythematosus. 5th ed. Philadelphia: Williams \& Wilkins, p 77, 1997.

4. Bekker-Mendez C, Yamamoto-Furusho JK, Vargas-Alarcon G, Ize-Ludlow D, Alcocer-Varela J, Granados J. Haplotype distribution of class II MHC genes in Mexican patients with systemic lupus erythematosus. Scand J Rheumatol 27: 373-6, 1998

5. Cervera R, Khamashta MA, Font J, Sebastiani GD, Gil A, Lavilla P, Domenech I, Aydintug AO, Jedryka-Goral A, de Ramon E, Galeazzi M, Haga HJ, Mathieu A, Houssiau F, Ingelmo M, Hughes GRV, and the European Working Party on Systemic Lupus Erythematosus. Systemic lupus erythematosus: Clinical and immunologic patterns of disease expression in a cohort of 1,000 patients. Medicine (Baltimore) 72: 113-24, 1993.

6. Colombo G, Brucato A, Coluccio E, Compasso S, Luzzana C, Franceschini F, Quinzanini M, Scorza R. DNA typing of maternal HLA in congenital complete heart block: Comparison with systemic lupus erythematosus and primary Sjogren's syndrome. Arthritis Rheum 42: 1757$64,1999$.

7. Galeazzi M, Annunziata P, Sebastiani GD, Bellisai F, Campanella V, Ferrara GB, Font J, Houssiau F, Passiu G, de Ramon-Garrido E, Fernandez-Nebro A, Bracci L, Scorza R, Puddu P, Jedryka-Goral A, Smolen J, Tincani A, Carcassi C, Morozzi G, Marcolongo R, and ECAISLE. Antiganglioside antibodies in a large cohort of European patients with systemic lupus erythematosus: Clinical, serological, and HLA class II gene association. J Rheumatol 27: 135-41, 2000.

8. Galeazzi M, Morozzi G, Sebastiani GD, Bellisai F, Marcolongo R, Cervera R, de Ramon-Garrido E, Fernandez-Nebro A, Houssiau F, Jedryka-Goral A, Mathieu A, Papasteriades C, Piette JC, Scorza R, Smolen J, and ECAISLE. Anti-neutrophil cytoplasmic antibodies in 566 European patients with systemic lupus erythematosus: Prevalence, clinical associations and correlation with other autoantibodies. Clin Exp Rheum 16: 541-6, 1998

9. Galeazzi M, Sebastiani GD, Tincani A, Piette JC, Allegri F, Morozzi G, Bellisai F, Scorza R, Ferrara GB, Carcassi C, Font J, Passiu G, Smolen J, Papasteriades C, Houssiau F, Fernandez-Nebro A, de Ramon-Garrido E, Jedryka-Goral A, Marcolongo R, and ECAISLE. HLA class II associations of anticardiolipin and anti- $\beta 2 \mathrm{GPI}$ antibodies in a large series of European patients with systemic lupus erythematosus. Lupus 9: 47-55, 2000.

10. Galeazzi M, Sebastiani GD, Passiu G, Angelini G, Delfino L, Asherson RA, Khamashta MA, Hughes GR. HLA-DP genotyping in patients with systemic lupus erythematosus: Correlations with autoantibody subsets. J Rheumatol 19: 42-6, 1992.

11. Genetic diversity of HLA functional and medical implications. Proceedings of XII Histocompatibility Workshop and conference. In: Dominique Charron, ed. HLA EDK, vol. I, p 496, 1997.

12. Haldane JBS. The estimation and significance of the logarithm of a ratio of frequencies. Ann Hum Genet 20: 309-11, 1955.

13. Hatta Y, Tsuchiya N, Matsushita M, Shiota M, Hagiwara K, Kokunaga $\mathrm{K}$. Identification of the gene variations in human CD22. Immunogenetics 49: 280-6, 1999

14. Hochberg MC. The application of genetic epidemiology to systemic lupus erythematosus. J Rheumatol 14: 867-9, 1987.

15. Jarvinen $P$, Aho K. Twin studies in rheumatic diseases. Semin Arthritis Rheum 24: 19-28, 1994.

16. Jungerman M, Sanchez-Mazas A, Fichna P, Ivanova R, Charron D, Hors J, Djoulah S. HLA class II DRB1, DQA1 and DQB1 polymorphisms in the Polish population from Wielkopolska. Tissue Antigens 49: 624-8, 1997.

17. Kimura A, Sasazuki T. Eleventh International Histocompatibility Workshop reference protocol for the HLA-DNA typing technique. In: Tsuji K, Aizawa M, Sasazuki T, eds. HLA 1991. Oxford: Oxford University Press, p 397, 1992.

18. Lawrence RC, Helmick CG, Arnett FC, Deyi RA, Felson DT, Giannini EH, Heyse SP, Hirsch R, Hochberg MC, Hunder GG, Liang MH, Pillemer SR, Steen VD, Wolfe F. Estimates of the prevalence of arthritis and selected musculoskeletal disorders in the United States. Arthritis Rheum 41: 778-99, 1998.

19. Lindqvist AKB, Alarcon-Riquelme ME. The genetics of systemic lupus erythematosus. Scand J Immunol 50: 562-71, 1999.

20. Lulli P, Sebastiani GD, Trabace S, Passiu G, Cappellacci S, Porzio F, Morellini M, Cutrupi F, Galeazzi M. HLA antigens in Italian patients with systemic lupus erythematosus: Evidence for the association of DQw2 with the autoantibody response to extractable nuclear antigens. Clin Exp Rheum 9: 475-9, 1991 .

21. Martin-Villa JM, Martinez-Laso J, Moreno-Pelayo MA, Castro-Panete MJ, Martinez-Quiles N, Alvarez M, de Juan MD, Gomez-Reino JJ, Arnaiz-Villena A. Differential contribution of HLA-DR, DQ, and TAP2 alleles to systemic lupus erythematosus susceptibility in Spanish patients: Role of TAP2 $* 01$ alleles in Ro autoantibody production. Ann Rheum Dis 57: 214-9, 1998.

22. Mehrian R, Quismorio FP, Strassmann G, Stimmler MM, Horwitz DA, Kitridou RC, Gauderman WJ, Morrison J, Brautbar C, Jacob CO. Synergistic effect between IL-10 and Bcl-2 genotypes in determining susceptibility to systemic lupus erythematosus. Arthritis Rheum 41: 596-602, 1998 .

23. Morel L, Rudofsky UH, Longmate JA, Wakeland EK. Polygenic control of susceptibility to murine systemic lupus erythematosus. Immunity 1 : 219-29, 1994.

24. Morel L, Tian X-H, Croker BP, Wakeland EK. Epistatic modifiers of autoimmunity in a murine model of lupus nephritis. Immunity 11: 131-9, 1999 .

25. Podrebarac TA, Boisert DM, Goldstein R. Clinical correlates, serum autoantibodies and the role of the major histocompatibility complex in French Canadian and non-French Canadian Caucasians with SLE. Lupus 7: 183-91, 1998

26. Reveille JD. Major histocompatibility complex class II and non-major histocompatibility complex genes in the pathogenesis of systemic lupus erythematosus. In: Lahita RG, ed. Systemic lupus erythematosus. San Diego: Academic Press, p 67, 1999

27. Reveille JD, Moulds JM, Ahn C, Friedman AW, Baethge B, Roseman J, Straaton KV, Alarcon GS. Systemic lupus erythematosus in three ethnic groups. I. The effects of HLA class II, C4 and CR1 alleles, socioeconomic factors, and ethnicity at disease onset. Arthritis Rheum 41: 1161-72, 1998.

28. Rood MJ, van Krugten MV, Zanelli E, van der Linden MW, Keijsers V, Schreuder GMT, Verduyn W, Westendorp RGJ, de Vries RRP, Breedveld FC, Verweij CL, Huizinga TWJ. TNF-308A and HLA-DR3 alleles contribute independently to susceptibility to systemic lupus erythematosus. Arthritis Rheum 43: 129-34, 2000.

29. Sebastiani GD, Galeazzi M, Tincani A, Piette JC, Font J, Allegri F, Mathieu A, Smolen J, de Ramon-Garrido E, Fernandez-Nebro A, Jedryka-Goral A, Papasteriades C, Morozzi G, Bellisai F, De Pita O, Marcolongo R, and ECAISLE. Anticardiolipin and anti- $\beta 2 \mathrm{GPI}$ antibodies in a large series of European patients with systemic lupus erythematosus: Prevalence and clinical associations. Scand J Rheumato 28: 344-51, 1999 .

30. Shai R, Quismorio FP Jr, Li L, Kwon OJ, Morrison J, Fallace DJ, Neuwelt CM, Brautbar C, Gauderman WJ, Jacob CO. Genome-wide 
screen for systemic lupus erythematosus susceptibility genes in multiplex families. Hum Mol Genet 8: 639-44, 1999.

31. Smolen JS, Klippel JH, Penner E, Reichlin M, Steinberg AD, Chused TM, Scherak O, Graninger W, Hartter E, Zielinscki CC. HLA-DR antigens in systemic lupus erythematosus: Association with specificity of autoantibody responses to nuclear antigens. Ann Rheum Dis 46: 457-62, 1987.

32. Tan EM, Cohen AS, Fries JF, Masi AT, McShane DJ, Rothfield NF, Schaller JG, Talal N, Winchester RJ. The 1982 revised criteria for the classification of SLE. Arthritis Rheum 25: 1271-7, 1982

33. Tanaka Y, Nakashima H, Hisano C, Kohsaka T, Nemoto Y, Niiro H, Otsuka T, Otsuka T, Imamura T, Niho Y. Association of the interferon- gamma receptor variant (Val14Met) with systemic lupus erythematosus. Immunogenetics 49: 266-71, 1999.

34. Tarassi K, Carthy D, Papasteriades C, Boki K, Nikolopoulou N, Carcassi C, Ollier WE, Hajeer AH. HLA-TNF haplotype heterogeneity in Greek SLE patients. Clin Exp Rheumatol 16: 66-8, 1998.

35. Tsao BP, Cantor RM, Grossman JM. PARP alleles within the linked chromosomal region are associated with systemic lupus erythematosus. J Clin Invest 103: 1135-40, 1999.

36. Wu J, Edberg JC, Redecha P, Bansal V, Guyre PM, Coleman K, Salmon JE, Kimberly RP. A novel polymorphism of Fc $\gamma$ RIIIa (CD16) alters receptor function and predisposes to autoimmune disease. J Clin Invest 100: 1059-70, 1997. 